\title{
CHRONIC MYELOGENOUS LEUKAEMIA IN INFANCY
}

\author{
BY \\ EDWARD G. FOX and JANET L. P. HUNTER \\ From the Paediatric Unit, Stobhill Hospital, Glasgon
}

(RECEIVED FOR PUBLICATION APRIL 16, 1954)

Chronic myelogenous leukaemia is an uncommon disease in infancy and is usually termed congenital in cases seen at or within a few days after birth. The latter do not appear to differ from those seen later except that they are believed to have started during intra-uterine life, and Kelsey and Andersen (1939) have laid down certain criteria for the diagnosis, which might be briefly stated as symptoms present at, or within a few days after birth accompanied by a disease process which could be reasonably concluded to have started during intra-uterine life. The condition is not transmitted from mother to foetus; Forkner (1938) collected 21 cases of chronic myelogenous leukaemia associated with pregnancy where the infant was healthy.

The clinical picture is one of hyperleukocytosis with immature forms of the myeloid series. There is a constant thrombocytopenia in all cases. The spleen is markedly enlarged, as is also the liver but to a lesser extent. Varying degrees of haemorrhagic manifestations are always seen and are frequently the initial sign. This tendency to bleed is more in keeping with the picture of acute leukaemia. Death is usually due to haemorrhage. The lymph nodes are not constantly enlarged but enlarged cervical nodes have been recorded. The average duration of the disease appears to be about one year irrespective of treatment.

Poncher, Weir and Limarzi (1942) recorded a case of congenital leukaemia in an infant aged 6 weeks. The early symptom was progressive enlargement of the abdomen and petechiae of the eyelids and mouth. This patient was treated with blood transfusions and $x$-ray irradiation using the spray technique. The infant died at 3 months. Cross (1944) reported two cases under 1 year from a series of six cases of chronic myelogenous leukaemia and in addition mentioned 16 cases collected from the literature between 1921 and 1942 . The ages of these latter cases ranged from newborn to 3 months. Keith (1945) described the case of a 3-month-old infant whose initial symptom was rectal bleeding and was found to have an enlarged spleen and liver with slight enlargement of the cervical lymph nodes. This patient survived for 12 months and was treated with small blood transfusions. Cooke (1953) reported three cases under 1 year from a series of 15 cases of chronic myelogenous leukaemia in childhood. Two of these babies were aged 3 months and one was aged 8 months. These three cases were treated with blood transfusions and the average survival time was one year. The treatment was also discussed in this paper, and Cooke concluded that benzol, arsenic, urethane, radio-active phosphorus and irradiation with $\mathrm{x}$-rays are best confined to periods during which definite symptoms, such as splenic enlargement or pressure symptoms, require relief. The best results were obtained from $x$-ray therapy. Anaemia and haemorrhagic symptoms were somewhat relieved by blood transfusions.

A further case of this disease in an infant under 1 year is described here. The mode of onset appeared to be unusual.

\section{Case Report}

A girl aged 9 months had recurrent swelling of the fingers and dorsal surfaces of both hands during the previous three months. Her mother thought that the condition was connected with the administration of sulphonamide for a respiratory tract infection. The baby had been quite well otherwise. The mother had had a course of thiouracil for a toxic goitre before her pregnancy with a moderate result and no ill effects.

On clinical examination the baby was seen to be a well nourished infant who appeared somewhat irritable. The fingers and dorsal surfaces of both hands were slightly puffy and rather blue. There was no tenderness and the finger joints were freely mobile. The swelling was confined to the phalanges and metacarpal bones. There was a small area of bruising around both nipples. The spleen was hard and enlarged about two fingerbreadths. The liver was just palpable. The lymph nodes in the neck and axillae were slightly enlarged. No other abnormal findings were detected. The temperature was normal but subsequently there were elevations to $100^{\circ} \mathrm{F}$. for periods of two to three days. The urine was normal. The Mantoux test ( 1 in 1,000 O.T.) was negative but a crop of petechiae appeared around the site of the 
injection. Radiographs of the chest, long bones and hands were negative. A blood examination gave Hb $70 \%$ (Sahli), red blood cells 3,900,000 per c.mm., white blood cells 80,400 per c.mm. (undifferentiated blast cells $0.5 \%$, myeloblasts $0 \%$, promyelocytes $0.5 \%$, myelocytes $5.5 \%$, metamyelocytes $5 \%$, polymorphonuclear cells $46.5 \%$, lymphocytes $28.5 \%$, monocytes $8 \cdot 5 \%$ ), platelets 3,000 per c.mm., Group $\mathrm{O}$, Rh-positive. An iliac crest puncture was carried out and was followed by marked bleeding into the surrounding tissues. The marrow film showed myeloblasts $1.2 \%$, promyelocytes $5.8 \%$ myelocytes $43.4 \%$, metamyelocytes $7 \cdot 6 \%$, polymorphonuclears $32.4 \%$, basophilic normoblasts $0.2 \%$, polychromatic normoblasts $4.2 \%$, orthochromatic normoblasts $5 \cdot 2 \%$.

During the baby's stay in hospital there was little change in her general condition. The spleen and nodes became larger. A fine purpuric rash appeared during the second week, mainly over the face and chest. She was given a blood transfusion and discharged home after two and a half months in hospital. The differential white cell count on discharge showed little change since admission. The fingers and hands had returned to normal and a further radiograph was negative. She attended the out-patient clinic during the following five months, remaining quite bright and active. The haemorrhagic signs became much more marked and she had extensive areas of ecchymosis with a widespread purpuric rash. The white blood cells numbered over 100,000 per c.mm. on several occasions, the number of primitive cells increased and the platelets were scanty or absent. A further blood transfusion was given with little benefit and no improvement in the haemorrhagic tendency.

She was readmitted at the end of five months as her condition had deteriorated. A differential white cell count at the time showed an increase in the primitive cells. Radiographs of the long bones were again negative. As the disease had become acute it was decided, with little hope of success, to try the effect of A.C.T.H. An initial dose of $20 \mathrm{mg}$. followed by $10 \mathrm{mg}$. daily was given for 14 days. No change in her general condition was noted and there was no alteration in the blood picture. She was allowed home following a third blood transfusion.

She was observed from time to time during the following three months. The spleen became much larger and lymph nodes could be felt in the abdomen. Though the child remained fairly active it was obvious that the increase in size of the spleen was causing discomfort. It was decided to readmit her to hospital with a view to $x$-ray therapy. On this occasion a differential white cell count showed undifferentiated blast cells $2 \%$, myeloblasts
$6.5 \%$, promyelocytes $12.5 \%$, myelocytes $10.5 \%$, metamyelocytes $5 \%$, polymorphonuclears $50 \%$, lymphocytes $11.5 \%$, monocytes $2 \%$. Platelets numbered 15,000 per c.mm. Three days after admission she collapsed and died within a few minutes.

\section{Necropsy Report}

The essential findings were as follows:

The lungs showed numerous small haemorrhages and a few firm consolidated foci suggestive of leukaemic infiltration. The hilar glands were slightly enlarged and fleshy.

The spleen was greatly enlarged, pink and soft, with innumerable small pale follicles scattered throughout.

The mesenteric nodes were enlarged. Their cut surface was pink with paler areas and occasional haemorrhages.

The liver was enlarged and pink with pale trabeculations in parts.

The vessels of the circle of Willis were normal. There was an extensive haemorrhage in the right lobe of the cerebellum, and it had ruptured into the subarachnoid space. A smaller haemorrhage was in the left cerebral hemisphere above the lateral ventricle.

The pulp of the spleen was extensively infiltrated by cells of the myeloid series but the Malpighian bodies were still distinct. All members of the myeloid series were present, myeloblasts and myelocytes predominating; eosinophils were plentiful but basophils were very scanty. Numerous mitotic figures were seen. There were few, if any, primitive red cells. The appearances were typical of chronic myeloid leukaemia. Leukaemic infiltration similar in type was found in lungs, liver, kidneys and lymph nodes.

\section{Summary}

A case of chronic myelogenous leukaemia in an infant aged 9 months is described.

The case was treated with small blood transfusions and A.C.T.H. It was doubtful if the treatment influenced the course of the disease.

The literature is briefly reviewed.

We wish to thank Dr. J. L. Markson for his assistance in the interpretation of the blood films and Dr. $\mathrm{H}$. Thompson for the necropsy and histological reports.

\section{ReFERENCES}

Cooke, J. V. (1953). J. Pediat., 42, 537.

Cross, F. S. (1944). Ibid., 24, 191.

Forkner, C. E. (1938). Leukemia and Allied Disorders. New York. Keith, H. M. (1945). Amer. J. Dis. Child., 69. 366.

Kelsey, W. M. and Andersen, D. H. (1939). Ibid., 58. 1268.

Poncher, H. G., Weir, H. F. and Limarzi, L. R. (1942). J. Pediat. 21, 73 . 